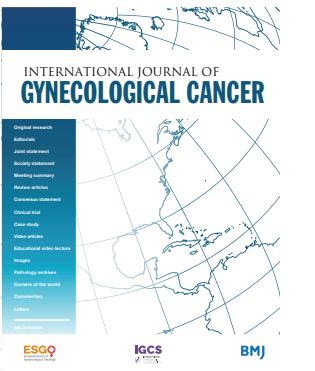

Gynecologic Oncology and Reproductive Medicine, The University of Texas MD Anderson Cancer Center, Houston, Texas, USA

\section{Correspondence to} Dr Larissa A Meyer, Gynecologic Oncology and Reproductive Medicine, The University of Texas MD Anderson Cancer Center, Houston, TX 77030, USA; Imeyer@mdanderson.org

Received 14 April 2021 Accepted 16 April 2021 Published Online First 7 May 2021

\section{SLinked}

- http://dx.doi.org/10.1136/ ijgc-2021-002475

Check for updates

C IGCS and ESGO 2021. No commercial re-use. See rights and permissions. Published by BMJ.

To cite: Harrison RF, Meyer LA. Int J Gynecol Cancer 2021;31:807.

\title{
Financial toxicity is common among gynecologic cancer patients
}

Ross F Harrison, Larissa A Meyer (ID

In the USA, many patients experience unexpected out-of-pocket spending following a cancer diagnosis, including direct medical costs from health insurance plan's cost-sharing requirements. The impact of these financial burdens may be exacerbated by lost income due to cancer treatment. This economic hardship leads to distress and concern about the cost of treatment, as well as the adoption of coping strategies to help manage financial hardship. These three domains-increased medical expenses coupled with lost income, the stress resulting from increased costs, and the behavioral changes used-together describe financial toxicity. ${ }^{1}$

The study by Esselen et al in this month's issue builds on their prior work characterizing financial hardship among patients diagnosed with a gynecologic cancer. ${ }^{2}$ The authors performed a secondary analysis of prospectively collected data, combining responses of two patient cohorts ${ }^{34}$ with the Comprehensive Score for Financial Toxicity (COST) survey, a validated patientreported outcome measure designed to measure financial distress (Table 1). ${ }^{5}$ Esselen and colleagues estimate that nearly half of patients experience some form of financial hardship. Despite the demographic and economic differences in the two cohorts, the authors found no differences in the proportions of patients reporting moderate or severe financial toxicity.

Severe financial distress was more common among those recently diagnosed or undergoing active treatment, suggesting that the economic hardship experienced by patients is closely linked with the intensity of treatment. To what degree does financial distress change over the course of cancer treatment? Patients being treated for early stage endometrial or cervical cancer might expect relief from the financial toxicity following frontline treatment, even if it were to involve multiple modalities of treatment. But what about patients with recurrent or metastatic cancer who are often treated continuously with systemic therapy for months or years? Does the financial toxicity of cancer treatment have a cumulative effect? As the authors acknowledge, their investigation's cross-sectional design limits our insight into these important questions.

In the cohort studied, one in five patients experiencing severe financial toxicity admitted to medication non-adherence. Changing spending habits or borrowing money was even more common. If a recommended treatment had a physical side effect that occurred with such frequency, clinicians likely would feel compelled to discuss it before initiating that regimen, present alternatives to consider, or at least describe a strategy to mitigate that toxicity. Admittedly, this inconsistency in discussing physical but not financial toxicities from cancer treatment may exist because patients and clinicians can find such conversations difficult. Limited time with competing priorities, difficulty in predicting the relative cost of treatment alternatives, or lack of awareness of viable solutions have been cited by clinicians as barriers to initiating cost conversations. However, patients face different and an altogether more difficult set of obstacles to raising the issue of cost in treatment planning. With this in mind, we would encourage clinicians to normalize the topic of cost and value in conversation with patients. A good way to start may be to simply inquire: "Have you been worried about the cost of your treatment?"

Contributors RH and LAM contributed to the writing of this editorial.

Funding This study was funded by National Cancer Institute (5T32CA101642, K07CA201013).

Competing interests None declared.

Patient consent for publication Not required.

Provenance and peer review Not commissioned; externally peer reviewed.

ORCID iD

Larissa A Meyer http://orcid.org/0000-0002-2687-7463

\section{REFERENCES}

1 Altice CK, Banegas MP, Tucker-Seeley RD, et al. Financia hardships experienced by cancer survivors: a systematic review. J Natl Cancer Inst 2017;109. doi:10.1093/jnci/ djw205. [Epub ahead of print: 20 Oct 2016].

2 Esselen KM, Gompers A, Hacker MR, et al. Evaluating meaningful levels of financial toxicity in gynecologic cancers. Int J Gynecol Cancer 2021;31:801-6.

3 Liang MI, Pisu M, Summerlin SS, et al. Extensive financial hardship among gynecologic cancer patients starting a new line of therapy. Gynecol Oncol 2020;156:271-7.

4 Bouberhan S, Shea M, Kennedy A, et al. Financial toxicity in gynecologic oncology. Gynecol Oncol 2019;154:8-12.

5 de Souza JA, Yap BJ, Hlubocky FJ, et al. The development of a financial toxicity patient-reported outcome in cancer: the COST measure. Cancer 2014;120:3245-53. 